\title{
Development of electrochemical sensor based on graphene nanocomposite for determination of $\beta$-agonists
}

\author{
Y. Poo-arporn ${ }^{1}$, S. Pakapongpan ${ }^{2}$, R. P. Poo-arporn ${ }^{3}$ \\ ${ }^{1}$ Synchrotron Light Research Institute, 111 University Avenue, Nakhon Ratchasima 30000, Thailand, \\ ${ }^{2}$ Thailand Organic and Printed Electronics Innovation Center, National Electronics and Computer \\ Technology Center, NSTDA, Pathum Thani 12120, Thailand \\ ${ }^{3}$ Biological Engineering Program, Faculty of Engineering, King Mongkut's University of Technology \\ Thonburi, Bangkok 10140, Thailand \\ rungtiva.pal@kmutt.ac.th
}

\begin{abstract}
:
This study reports the development of a reduced graphene oxide/iron oxide nanocomposite modified screen-printed electrode ( $\left.\mathrm{rGO}-\mathrm{Fe}_{3} \mathrm{O}_{4} / \mathrm{MSPE}\right)$ as a novel system for the preparation of electrochemical sensing for $\beta$-agonists determination. To fabricate the sensor, $\mathrm{Fe}_{3} \mathrm{O}_{4}$ was attached on the $\mathrm{rGO}$ surface by covalent linking to obtain $\mathrm{rGO}-\mathrm{Fe}_{3} \mathrm{O}_{4}$ nanocomposite. The nanocomposite was dropped on the surface of SPE to obtain nanocomposite film forming on the electrode. Adsorption of $\mathrm{Fe}_{3} \mathrm{O}_{4}$ on $\mathrm{rGO}$ and structural property were characterized by $x$-ray absorption near-edge structure (XANES) technique. The electrocatalytic response to $\beta$-agonists and the performance of the sensor were investigated by means of differential pulse voltammetry (DPV). The proposed sensor exhibited great electrocatalytic activity and fast response to $\beta$-agonists. The linear relation in the range from $1 \mu \mathrm{M}$ to $20 \mu \mathrm{M}$ with a detection limit of $75 \mathrm{nM}$ based on $\mathrm{S} / \mathrm{N}=3$. The sensor exhibited a sensitivity of 116.4 $\mu \mathrm{A} / \mathrm{mM}$
\end{abstract}

Key words: $\beta$-agonists, sensor, graphene, nanocomposite, electrochemistry.

\section{Introduction}

Graphene possesses many unique features such as large surface area, good electrical, thermal, and mechanical properties that make them has been widely employed for electrochemical analysis [1-2]. In addition, varieties of hybrid materials between graphene and other materials with new functions are promising for utilization in various applications. The integration of iron oxide and graphene oxide may offer a hybrid nanocomposite with synergistic properties improving the catalytic activity and provide more surface area and good biocompatibility.

B-agonists such as ractopamine (RAC) is used illegally as feed additive for growth promotion in farm animals, and such practices can lead to potential risks to human health [3]. Consequently, RAC is an illegal growth promoter for swine and is included in the prohibited list of World Anti-Doping Agency. In this work, the potential applicability of employing $\mathrm{rGO}^{-} \mathrm{Fe}_{3} \mathrm{O}_{4}$ nanocomposite as a potential candidate for the construction of electrochemical sensor for leanness-enhancing agent was proposed.

\section{Experiment}

The $\mathrm{Fe}_{3} \mathrm{O}_{4} \mathrm{NPs}$ was immobilized on $\mathrm{GO}$ using EDC and NHS as coupling agents by the formation of an amide link between the amino group of $\mathrm{Fe}_{3} \mathrm{O}_{4} \mathrm{NPs}$ and the carboxyl group of GO. An $\mathrm{rGO}^{-}-\mathrm{Fe}_{3} \mathrm{O}_{4}$ based on glucose reduction was prepared. . Finally, the $5 \mu \mathrm{l} \mathrm{rGO-}$ $\mathrm{Fe}_{3} \mathrm{O}_{4}$ nanocomposite solution was dropped onto the MSPE surface.

XANES prepared samples were collected at Synchrotron Light Research Institute, Thailand. The $\mathrm{Fe} \mathrm{K}$-edge XANES were measured at BL2.2: TRXAS using $\mathrm{Si}$ (111) and NMOS detector [4].

All electrochemical experiments were performed with a potentiostat (Metrohm Autolab PGSTAT302N, Ecochemie, Netherlands) in a conventional three-electrode electrochemical cell using a screen-printed electrode (SPE) as a working electrode, a platinum electrode as a 
counter electrode and an $\mathrm{Ag} / \mathrm{AgCl}$ saturated $\mathrm{KCl}$ as the reference electrode.

\section{Results and Discussion}

The structural property of magnetic material in graphene nanocomposite was investigated through Fe K-edge XANES spectra (Fig. 1). At the energy between $7150-7170 \mathrm{eV}, \mathrm{GO}-\mathrm{Fe}_{3} \mathrm{O}_{4}$ exhibited small pre-edge and a board white-line peaks. These characteristic features suggested the combination of the iron oxide compounds. Linear combination fitting (LCF) analysis was used to decompose XANES spectrum. The predictors of standard iron-oxide compounds and iron including $\mathrm{FeO}, \mathrm{Fe}_{3} \mathrm{O}_{4}, \mathrm{Fe}_{2} \mathrm{O}_{3}$ and $\mathrm{Fe}$ foil were used. The combination of model spectra displayed the mixed phase between $\mathrm{Fe}_{2} \mathrm{O}_{3}(80.8 \%)$ and $\mathrm{Fe}_{3} \mathrm{O}_{4}(16.2 \%)$. The existing of $\mathrm{Fe}_{3} \mathrm{O}_{4}$ phase in $\mathrm{GO}-\mathrm{Fe}_{3} \mathrm{O}_{4}$ nanocomposite confirmed its magnetic character.

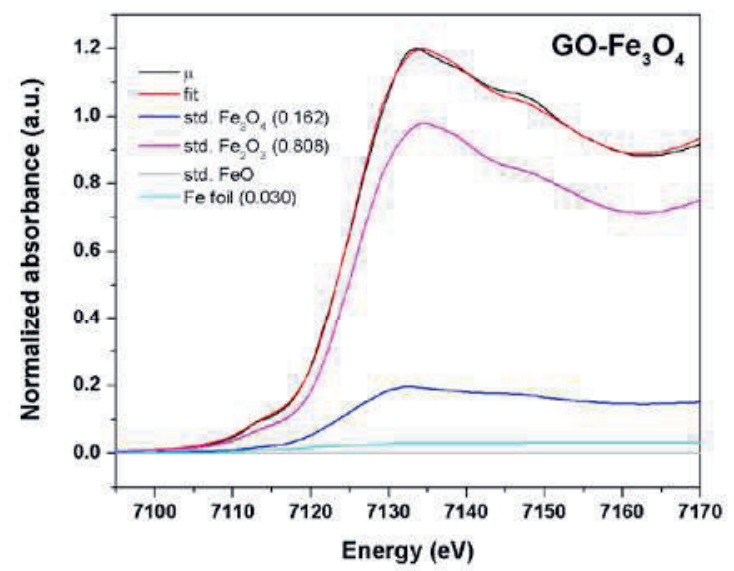

Fig. 1. Linear combination fitting analysis of GO$\mathrm{Fe}_{3} \mathrm{O}_{4}$ using $\mathrm{FeO}, \mathrm{Fe}_{3} \mathrm{O}_{4}, \mathrm{Fe}_{2} \mathrm{O}_{3}$ and $\mathrm{Fe}$ foil as the predictors.

The differential pulse voltammetry (DPV) was used for determination of ractopamine with highly sensitive and low detection limit, under the optimum conditions at potential range from 0 to $1.0 \mathrm{~V}$. Fig. 2A shows the typical DPV response for different concentrations of ractopamine from $1 \mu \mathrm{M}$ to $100 \mu \mathrm{M}$. The oxidation peak currents were increases proportional with the increasing of ractopamine concentrations, and the resulting calibration plots are a good linear over the range from 1 $\mu \mathrm{M}$ to $20 \mu \mathrm{M}$. The linear regression equations were $I_{p}(\mu A)=0.1164 x+0.3435\left(R^{2}=0.98\right)$ (Fig. 2B). The detection limit was estimated to be $75 \mathrm{nM}$ at a signal-to-noise ratio $(\mathrm{S} / \mathrm{N})$ of 3 .

\section{Conclusions}

We have successfully employed $\mathrm{rGO}-\mathrm{Fe}_{3} \mathrm{O}_{4}$ nanocomposite modified MSPE as a potential candidate for the construction of RAC sensor. The used of $\mathrm{Fe}_{3} \mathrm{O}_{4} \mathrm{NPs}$ not only increase the surface area but also have the paramagnetic property which makes them easily manipulated by an external magnetic field to improve stability of the sensor. The nanocomposite shows an excellent electrocatalytic activity, wide range and low detection limit. Moreover, the potential applicability of the nanocomposite modified MSPE as a novel disposable electrochemical sensing platform for $\beta$-agonists drugs.
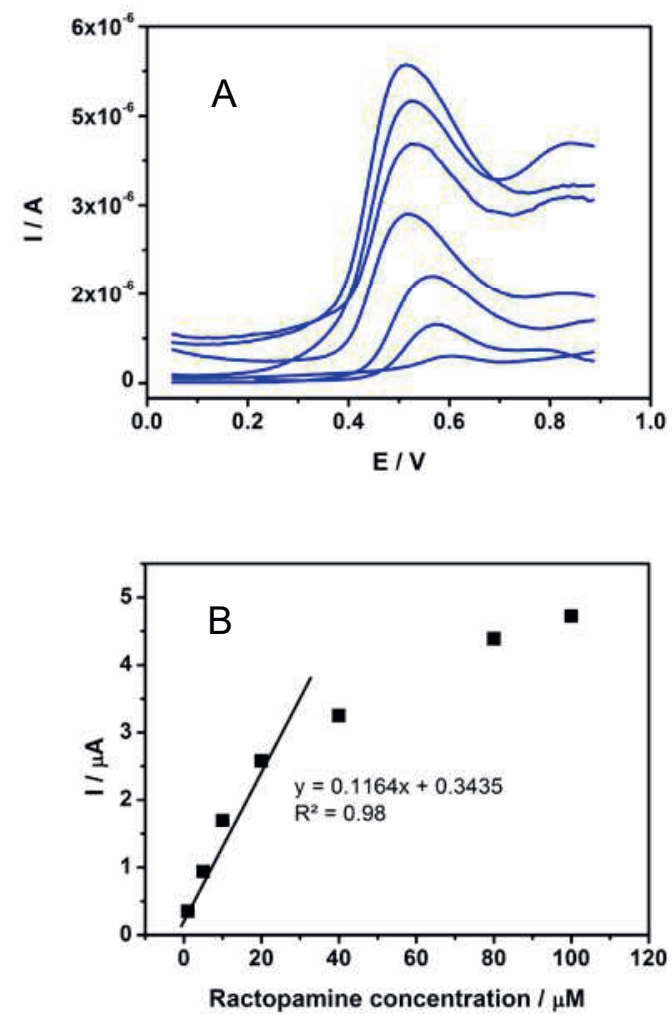

Fig. 2. (A) Differential pulse voltammograms of $\mathrm{rGO} / \mathrm{Fe}_{3} \mathrm{O}_{4} / \mathrm{MSPE}$ at the ractopamine concentration from 1 to $100 \mu M$. (B) The calibration curve between the peak current and ractopamine concentration.

\section{References}

[1] M. J. Allen, V. C. Tung and R. B. Kaner, Honeycomb Carbon: A Review of Graphene, Chemical Reviews 110, 132-145 (2010).

[2] Y. Shao, J. Wang, H. Wu, J. Liu, I. A. Aksay and Y. Lin, Graphene Based Electrochemical Sensors and Biosensors: A Review, Electroanalysis 22, 1027-1036 (2010).

[3] M. X. Xu, X. L. Qian, K. Zhao, A. P. Deng, J. G. $\mathrm{Li}$, Flow injection chemiluminescent competitive immunoassay for the -adrenergic agonist salbutamol using carboxylic resin beads and enzymatic amplification, Sensors and Actuator B: Chemical 215, 323-329 (2015).

[4] Y. Poo-arporn, P. Chirawatkul, W. Saengsui, S. Chotiwan, S. Kityakarn, S. Klinkhieo, J. Hormes, P. Songsiriritthigu, Time-resolved XAS (BonnSUT-SLRI) beamline at SLRI, Journal of Synchrotron Radiation 19, 937-943 (2012). 